\title{
RARE SPECIES OF ERIOPHYID MITES (DIPTILOMIOPIDAE: ERIOPHYIDAE: ACARI) FROM SOUTHERN INDIA
}

\author{
G. Umapathy ${ }^{1}$ and M. Mohanasundaram \\ Centre of Advanced Studies in Entomology, Tamil Nadu Agricultural University, Coimbatore, Tamil Nadu 641003, India. \\ ${ }^{1}$ Email: umapathyg@ rediffmail.com
}

\begin{abstract}
In a survey conducted in various reserve forests of southern India, two rare species of diptilomiopid eriophyid mites (Diptilomiopidae) have been recorded for the first time in India -- Asetadiptacus carmonae sp. nov. (ex. Salacia sp. (?) Hippocrartaceae) and Levonga attakattiensis sp. nov. The systematic account of the new mite species with suitable line drawings is provided in the paper.
\end{abstract}

\section{Keywords}

Eriophyid, Diptilomiopid, Asetadiptacus carmonae, Levonga attakattiensis, vagrants, new species, southern India

\section{Abbreviations}

TNAU - Tamil Nadu Agricultural University, Coimbatore

\section{Introduction}

During the course of a biodiversity programme, an extensive survey was undertaken during 1998-1999 to study the fauna of eriophyid mites which remain unexplored and unidentified. A concise statistics on the eriophyid fauna indicate that only less than five per cent of the total tropical fauna have been reported leaving around 18,000 to 19,000 species to be described (Amrine \& Stasny, 1994). In our investigation, we have encountered two new species of eriophyid mites viz., Asetadiptacus carmonae sp.nov. and Levonga attakattiensis sp.nov. These two new mite species are the second species ever recorded in their respective genera and are the first Indian reports. Adequate line drawings are provided for the new mite species besides detailed taxonomic account.

All measurements are expressed in microns.

\section{Asetadiptacus carmonae sp. nov.}

(Figs. 1-9)

\section{Material examined}

Types: One holotype slide (female marked) and one paratype slide with both sexes, Puthur Reserve Forest, Karnataka, Ex. Salacia sp. (?) (Hippocrataceae), Coll. G. Umapathy, TNAU No. 43.

\section{Etymology}

The new species is named after M.M. Carmona who coined the genus.

\section{Diagnostic features}

The new species is differentiated from the type Asetadiptacus emliae Carmona (1970) by its shield design and smooth female genital cover flap.

Female: 180 long, 75 wide, 50 thick. Rostrum 34 long, pointing obliquely backward. Antapical seta two long. Shield 52 long, 65 wide, broadly conical; shield area involve several unclear or faint lines and troughs; median incomplete, extend up to $1 / 3$ 


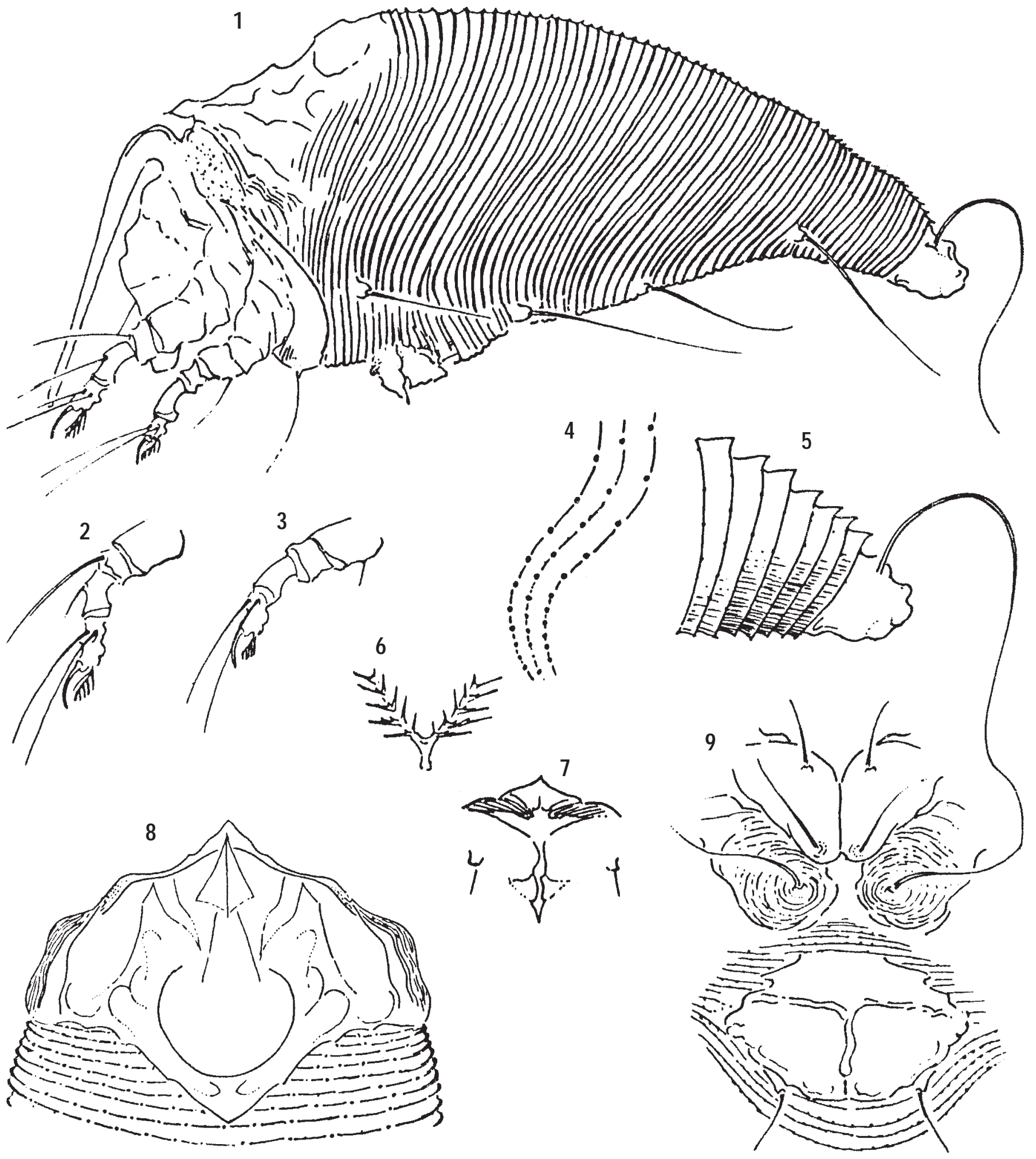

Figures 1-9. Asetadiptacus carmonae sp. nov.

1 - Lateral view of the mite; 2 - Foreleg; 3 - Hind leg; 4 - Lateral skin structure; 5 - Lateral view of caudal segment; 6 - Feather claw; 7 - Male genitalia; 8 - Dorsal view of the anterior; 9 - Female genitalia and coxal base 


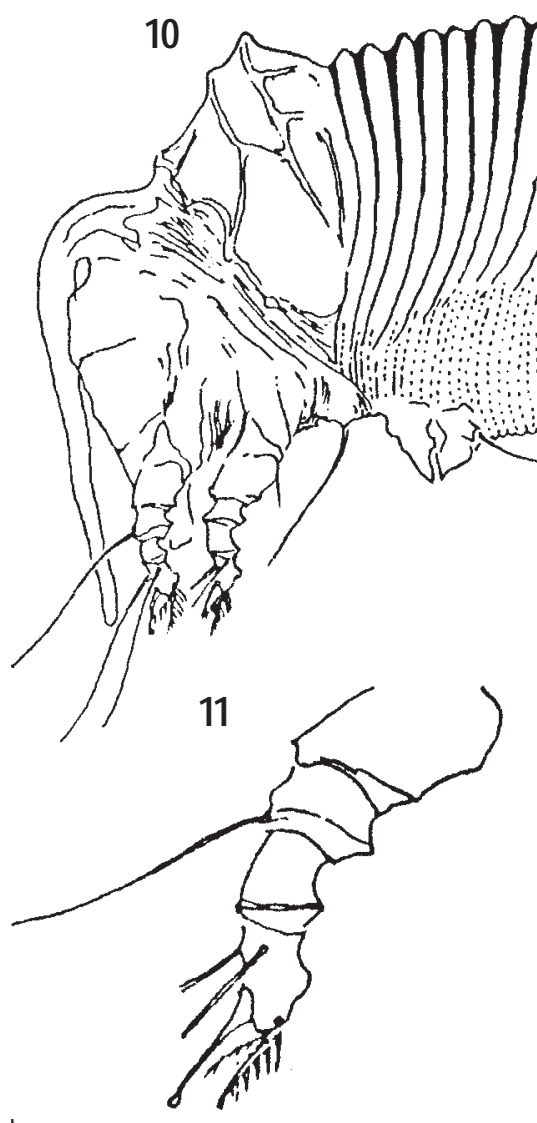

14
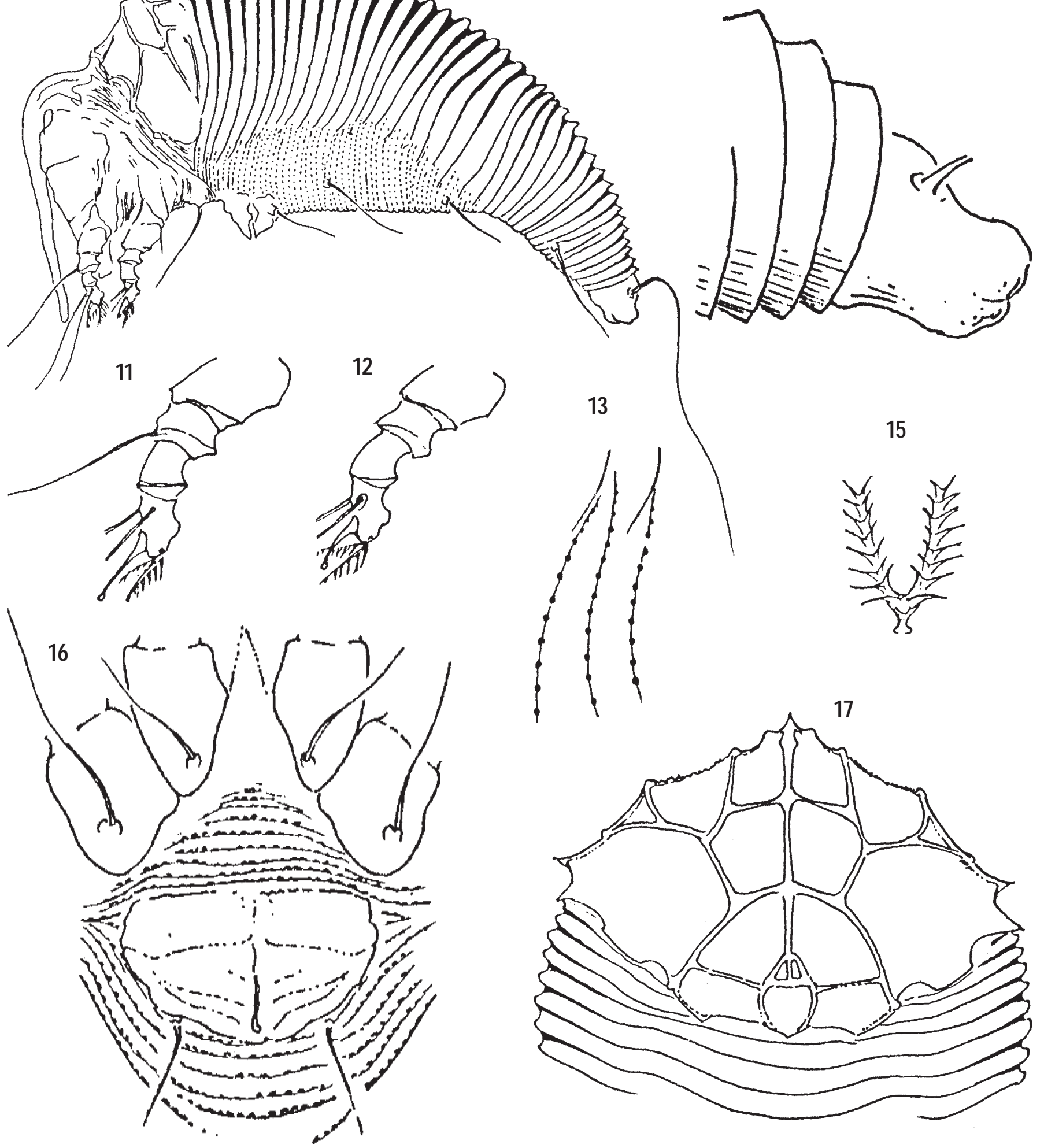

Figures 10-17. Levonga attakattiensis sp. nov.

10 - Lateral view of the mite; 11 - Foreleg; 12 - Hindleg; 13 - Lateral skin structure; 14 - Lateral view of caudal segment; 15 - Feather claw; 16 - Female genitalia and coxal base; 17 - Dorsal view of the anterior 
anterior; admedian and submedian lines incomplete, sinuate. Shield margin with numerous longitudinal lines. Dorsal tubercles and shield setae missing. Foreleg 38 long; tibia 8 long; tibial seta 5 long, placed at proximal 1/3; tarsus 7 long; fore femoral seta absent; claw 7 long, curved, blunt. Feather claw long, divided, five-rayed. Hind leg 35 long; tibia 7 long and tarsus 6 long; hind patellar setae missing. Forecoxa join centrally by a Y shaped mid-sternal line; anterior coxae connate for moderate length; hind coxae with numerous faint lines; coxae with usual setation. Setiferous coxal tubercles I, II and III are almost on longitudinal approximation.

Abdominal thanosome has about 60 undifferentiated rings; small, pointed microtubercles present throughout. Lateral seta 13 long on ring eight to ten; first ventral 35 long on ring 28; second ventral seta 15 long on ring 48; third ventral 25 long on ring eight from behind; caudal seta 40 long; accessory seta missing. Female genitalia 18 long, 26 wide, not oppressed to coxae. Coverflap smooth; genital seta short, eight long.

Male: 150 long, 62 wide, 48 thick. Genitalia 18 wide, seta five long.

\section{Remarks}

The mites are leaf vagrants.

\section{Levonga attakattiensis sp. nov.} (Figs. 10-17)

\section{Material examined}

Type: A holotype slide with the type marked. Attakatti Reserve Forest, Coimbatore District, Tamil Nadu, 15.vi.1999, ex. unidentified tree, Coll. G. Umapathy, TNAU No. 19.

\section{Diagnostic features}

The new mite species deviate from the type Levonga pappintongensis Manson (1984) due to its shield design, absence of shield seta and forecoxal setiferous tubercles. This is the second species described under this genus.

Female: 135-140 long, 55 wide. Rostrum 42 long, pointing down. Shield 23 long, 53 wide, shield surface has three rows of boxes in symmetrical fashion; posterior most sides of shield has toothlike projections. Dorsal tubercles and shield seta missing. Foreleg 37 long, tibia 7 long, tibial seta absent; tarsus 5 long; claw 5 long, knobbed, feather claw divided, eight-rayed; fore femoral seta absent. Hindleg 33 long, tibia 6 long, tarsus 4 long; hind femoral and hind patellar setae missing. Fore coxa widely separated; first setiferous tubercles missing; seta on tubercle 11, 15 long; second setiferous tubercles well ahead of transverse fine through third tubercles; seta on tubercle III, 33 long; coxal bases smooth.
Thanosome differentiated into about 50 smooth tergites and 110 microtuberculate sternites; tergite and sternite at the ratio of 1:1.5; dorsum has a median ridge and shallow trough on both sides. Lateral seta missing; first ventral 12 long on stenite 35; second ventral 10 long, on about ring 65; third ventral 12 long, on ring 12 from behind; caudal seta 35 long; accessory seta not seen. Female genitalia 20 long, 25 wide; coverflap has no obvious ribs. Genital seta 10 long.

Male: Not known.

\section{Remarks}

The mites are lower surface leaf vagrants.

\section{References}

Amrine, W. and A. Stasny (1994). Catalogue of the Eriophyoidea (Acarina:Prostigmata) of the World. Indira Publishing House, Michigan, U.S.A., 531pp.

Carmona, M.M. (1970). Asetadiptacus, a new genus: Family: Rhyncaphytoptidae (Acarina: Eriophyoidea). Acarologia 12(3): 527530 .

Manson, D.C.M. (1984). Eriophyoidea except Eriophyinae (Arachnida: Acari), pp. 123-124. Fauna of New Zealand - No. 5. Department of Science and Industrial Research. Wellington, New Zealand. 